\title{
Demonios e imaginación en Giordano Bruno
}

\section{Agustín G. Bianchi}

Universidad Nacional de General Sarmiento / CONICET, Argentina

Recibido el 15 de mayo de 2020; aceptado el 5 de junio de 2020.

\begin{abstract}
Resumen
Con Giordano Bruno (1548-1600) asistimos a la recuperación de doctrinas neoplatónicas y herméticas que conducen a una comprensión animista y dinámica de la naturaleza, así como a una exaltación del hombre en tanto conoce y actúa sobre el mundo. En el contexto de un universo vivo y animado, Bruno necesita mediaciones en el espacio que hay entre, por un lado, la naturaleza finita del hombre y, por el otro, la divinidad infinita explicada en la naturaleza para fundamentar la teoría mágica de sus obras latinas. Precisamente, la existencia de los demonios en los sistemas neoplatónicos viene a cumplir con este propósito.
\end{abstract}

Sostenemos que existe una continuidad entre la doctrina demonológica que Bruno presenta en su obra latina y la metafísica y cosmología de sus diálogos italianos. Esta continuidad se verifica en la presencia de dos categorías filosóficas importantes del pensamiento bruniano presente en la demonología del De magia naturali (1590): imaginación y vínculos. Así pues, en primer lugar, indagaremos la recepción de la doctrina neoplatónica en la demonología de los siglos XV y XVI, a partir de la cual Bruno desarrolla el marco teórico y filosófico de su doctrina demonológica. En segundo lugar, estudiaremos la naturaleza y función de los demonios en el De magia naturali y su relación con la imaginación y los vínculos en la filosofía del Nolano.

PALABRAS CLAVE: GIORDANO BRUNO, RENACIMIENTO, DEMONIOS, IMAGINACIÓN, VÍNCULOS.

\section{Demons and imagination in Giordano Bruno}

\begin{abstract}
With Giordano Bruno (1548-1600) we attend the recovery of Neoplatonic and Hermetic doctrines that lead to an animistic and dynamic understanding of nature, as well as an exaltation of man as who knows and acts on the world. In the context of a living and animated universe, Bruno needs mediations in the space between, on the one hand, the finite nature of man and, on the other hand, the infinite divinity explained
\end{abstract}


in nature to support the magic theory of his Latin work. Accurately, the existence of demons in Neoplatonic systems comes to fulfill that purpose.

I maintain that there is continuity between the demonological doctrine that Bruno presents in his Latin work and the metaphysics and cosmology of his Italian dialogues. This continuity is verified in the presence of two important philosophical categories of Bruneian thought which is in the demonology of De magia naturali (1590): the imagination and bonds. Thus, firstly, I will inquire about the reception of Neoplatonic doctrine in the demonology of the 15th and 16th centuries, from which Bruno develops the theoretical and philosophical framework of his demonological doctrine. Secondly, I will analyze the nature and function of the demons in De magia naturali and their relationship with the imagination and bonds in the Nolan philosophy.

KEYWORDS: GIORDANO BRUNO, RENAISSANCE, DEMONS, IMAGINATION, BONDS.

\section{Introducción}

En la Antigüedad, la existencia de los demonios (daimones) se encuentra documentada en obras tan disímiles como los poemas de Hesíodo, las tragedias de Esquilo, los diálogos de Platón y el Corpus hermeticum, entre otras. El vocablo daímon no poseía la carga negativa que en la actualidad otorgamos a la palabra demonio. De hecho, la actividad de los daimones y los theoi no fue objeto de una distinción rigurosa por mucho tiempo y, por lo tanto, la consideración de los demonios como exclusivamente "malignos" tendría que esperar hasta los primeros siglos de la era cristiana. Durante los siglos II y III la demonología -entendiendo por "demonología" al estudio de la naturaleza y la actividad de estos seres espirituales llamados daimones- se encontraba sumamente extendida en los autores helenísticos y era considerada una ciencia provechosa e, incluso, una forma de conocimiento natural. ${ }^{1}$

Para filósofos como Plutarco de Queronea (c. 45-120) y Jámblico de Calcis (c. 250-330) era de vital importancia que el sabio sepa diferenciar la actividad de los demonios (tanto de los "malignos" como de los "benéficos") de la actividad de las divinidades superiores. Asimismo, para la mentalidad helénica la mediación de los daímones era indispensable para que la relación entre los hombres y los dioses fuera posible. En este sentido, la necesidad de definir, clasificar, atraer o repeler demonios llevó a la demonología a un complejo desarrollo durante este periodo. Posteriormente, esta necesidad de una mediación demónica entre la divinidad y los hombres fue duramente criticada por autores cristianos como Eusebio de Cesarea (263-339) y Agustín de Hipona (354-430).

Pocos periodos de la historia se comparan al siglo II y III respecto al interés por esta doctrina como los siglos XV y XVI. Junto a la recuperación del pensamiento clásico, encontramos en el periodo renacentista un escenario favorable para el desarrollo de la magia natural, la alquimia, la astrología y, por supuesto, la demonología. ${ }^{2}$ Autores como Apuleyo (c. 125-185), Plotino (205-270), Porfirio (232-304), Proclo (412-485), y los mencionados Plutarco y Jámblico, son retomados para nutrir las nuevas doctrinas

\footnotetext{
1 Sobre los daímones en la Antigüedad remitimos a los estudios de Rodríguez Moreno, 1994; Cornford, 1957; Thorndike, 1923; y Luck, 1995. Debemos remarcar que estos dos últimos estudios dedican la mayor parte de su investigación a la magia en general y no sólo a la demonología. Sobre la demonología en la temprana modernidad, Clark, 1997.

2 La recepción de las ciencias ocultas en el Renacimiento fue estudiada por investigadores de renombre como Eugenio Garin, Daniel P. Walker y Frances A. Yates, entre otros. Respecto a la demonología en Bruno, Ignacio Gómez de Liaño aporta valiosas sugerencias -retomadas en este trabajo- en su edición de obras brunianas compiladas en Mundo. Magia. Memoria (Gómez de Liaño, 1982b).
} 
acerca de la actividad de los demonios de Marsilio Ficino (1433-1499), Cornelio Agrippa (1486-1535) y Giordano Bruno (1548-1600), entre otros.

En uno de sus tratados más editados, el De vita triplici, publicado en 1489, Marsilio Ficino presenta una medicina mágico-astrológica apoyada no sólo en doctrinas neoplatónicas sino también en postulados hermético-caldeos. A partir de esta obra, se inicia un amplio renacimiento de la magia que se introduce en toda Europa hasta llegar a la Modernidad. La magia astral presentada por el florentino impulsaría el debate acerca del trato con demonios por parte del hombre y la ambigua distinción entre magia naturalis y magia demoniaca. ${ }^{3}$

Uno de los continuadores de la corriente mágico-astrológica, si bien con significativas diferencias, es el filósofo naturalista Giordano Bruno. ${ }^{4}$ En efecto, una de las características que comparte Bruno con dicha corriente es la ausencia de un dualismo ontológico absoluto: macrocosmos y microcosmos se co-implican mutuamente. ${ }^{5}$ En otras palabras, la reivindicación de la materia y del universo, en tanto "vestigio" e imagen verdadera de la divinidad por parte de la filosofía nolana, encuentra su correlato en la cosmovisión mágico-animista de la realidad.

Tal como señalan Greif y Szapiro (2012), a lo largo de la segunda mitad del siglo XX los estudios brunianos podían distinguirse en dos líneas dominantes: aquella que destaca los aportes de la filosofía nolana en la configuración de la ciencia moderna, y aquella que destaca el aspecto mágico de Bruno y lo ubica en la tradición hermética renacentista. Así pues, y para poner un ejemplo, en el reciente estudio introductorio a su traducción de La cena de las cenizas (2015), Miguel Ángel Granada critica a la denominada "tesis Yates" -debido a la historiadora Frances Yates- por desembocar en una "completa desatención a la problemática estrictamente filosófica (metafísica, teología, epistemología, incluso filosofía natural y cosmología)" (2015: XX) presente en diálogos como La cena de las cenizas, De la causa, el principio y el uno y Del infinito: el universo y los mundos.

En el citado trabajo de Greif y Szapiro se exhorta a una superación de las limitaciones de ambas miradas dicotómicas -el Bruno "racional" y el Bruno "mágico"- que, lejos de tender a abandonar dichas perspectivas, debería articularlas en una mirada integral del filósofo italiano. En los últimos años, varios trabajos han ido en esa dirección, por ejemplo, el reciente estudio de Manuel Mertens que busca superar las lecturas de Felice Tocco (quien desatendería toda temática mágica y mnemotécnica presente en Bruno), Frances Yates (quien no abarcaría todas las obras mágicas del Nolano) y de Rita Sturlese (quien abandonaría toda conexión entre la obra mnemotécnica y la obra mágica brunianas) (Mertens, 2018: 25-26); y los trabajos de Stephen Clucas dirigidos a demostrar la unión entre los diálogos londinenses y la obra mnemotécnica en base a los supuestos metafísicos que ambos corpus tienen en común (2004: 7-8).

3 Sobre la influencia de la medicina mágico-astrológica ficiniana en la teoría y la práctica médica del Renacimiento del siglo XVI véase Hiro Hirai, 2012. Para un análisis sucinto de los elementos principales y las fuentes de la magia ficiniana remitimos a Copenhaver, 1987 y al artículo de De Garay, Magia y neoplatonismo en Ficino (2016). Sobre la magia natural y la magia demoniaca en el Renacimiento véase Clark, 1997: 214-251.

4 La tesis según la cual Bruno es un continuador de la corriente mágico-astrológica es postulada por Frances Yates en Giordano Bruno and the Hermetic Tradition, publicado originalmente en 1964. A lo largo de su investigación, la autora señala las diferencias entre las posturas de Ficino y de Bruno respecto al hermetismo y a la magia.

5 En el pensamiento de Bruno, la íntima relación entre macrocosmos y microcosmos encuentra su máxima expresión en el Spaccio de la bestia trionfante (1584), diálogo londinense que narra la asamblea de dioses olímpicos para reformar el cielo y sus estrellas. Esta reforma del macrocosmos derivará, según el propio Bruno, en una reforma del hombre o microcosmos. El motivo del macrocosmos-microcosmos tiene sus manifestaciones en otros autores renacentistas como Nicolás de Cusa (1401-1464), Marsilio Ficino, Pico della Mirandola (1463-1494), Paracelso (1493-1541) y el inglés Robert Fludd (1574-1637). Sobre la relación macrocosmos-microcosmos en el Renacimiento en general véase el estudio de Cassirer, Individuum und Kosmos in der Philosophie der Renaissance (1927). 
El presente trabajo pretende ser un aporte en esta dirección integradora del pensamiento de Giordano Bruno. De este modo, sostenemos como tesis de lectura que la demonología presentada por el Nolano en su obra latina no puede comprenderse sin la teoría de los vínculos y de la imaginación. Asimismo, la cosmología y ontología de los diálogos italianos sería el trasfondo metafísico de la teoría mágica y la doctrina demonológica de la obra latina.

Para ello, nos centraremos en las obras latinas De magia naturali (1590) y De vinculis in genere (1591). La división de nuestro trabajo responderá a los siguientes propósitos: 1) indicar las fuentes neoplatónicas y las principales teorías que nutren el marco filosófico de la demonología bruniana y, 2) señalar la relación existente entre la naturaleza ontológica de los demonios, la imaginación y los vínculos en las obras mencionadas del filósofo Nolano.

\section{La recepción de fuentes neoplatónicas en la demonología renacentista}

\subsection{La imaginación y la actividad de los demonios}

El objetivo de este apartado es presentar las fuentes neoplatónicas fundamentales para el desarrollo de la demonología renacentista en general, y de la demonología bruniana en particular. Los conceptos de espíritu fantástico, Eros y sympátheia serán esenciales para comprender el alcance de la idea de Amor vinculum vinculorum bruniano, la imaginación y la teoría de los vínculos en relación a la naturaleza de los demonios. Sin el marco teórico y filosófico que Bruno hereda del neoplatonismo, no es posible comprender la presencia de la demonología en su obra latina y, más específicamente, en su obra mágica.

Así pues, a los fines del trabajo, nos interesa señalar las fuentes de una de las teorías más importantes para comprender la demonología presente en los siglos XV y XVI: la imaginación (phantasía) como una facultad íntimamente ligada a la actividad de los demonios. Estas fuentes son el tratado Sobre los sueños (Peri enypnion o De insomniis) de Sinesio (c. 370-413) -citado varias veces en el De vita de Ficino-y el opúsculo Sobre la actividad de los demonios (Peri energeías daimónôn) de Miguel Psellos (c. 1018-1078) -traducido por Ficino como De daemonibus y citado por Bruno en el De magia naturali-. Como observaremos, la teoría de la imaginación de estos autores neoplatónicos les dará a los pensadores renacentistas un marco conceptual indispensable para comprender la naturaleza y el modo de operar de los demonios.

Sinesio sostiene que la imaginación (phantasía), o espíritu fantástico (Phantastikòn pneûma), "constituye la tierra de nadie entre la irracionalidad y la razón, entre lo incorpóreo y lo corpóreo, una frontera común entre ambos", y el medio a partir del cual lo divino se comunica con la naturaleza más degradada (De insomniis 137a: 264-265). A su vez, los demonios, al ubicarse también en la frontera entre "la irracionalidad y la razón" y "lo incorpóreo y lo corpóreo", encuentran en la imaginación la puerta de entrada para influenciar en los sentidos de los hombres (esto se desarrollará en los siguientes apartados). Por ello, Sinesio dice que los demonios son "imágenes reflejadas en el devenir de las cosas" (ibid. 137b: 265. Bastardilla nuestra), dando a entender su íntima relación con el ámbito de la imaginación. Giordano Bruno, en la obra latina De imaginum, signorum et idearum compositione (1591), cita casi textualmente la teoría de la imaginación del cirenaico. ${ }^{6}$

\footnotetext{
6 La mención se encuentra en el capítulo XIV, titulado De effectore imaginum: "Ex hisce manifestum est potentiam istam imaginum esse effectricem vel qua anima imaginum est effectrix. Ad cuius rei propositum Synesii Platonici sententiam in medium afferamus, qui de potestate phantasiae spiritusque phantastici ita disserit: «In vigilia doctor est homo, somniantem vero Deus ipse sui participem facit, quod assumimus ad vitae phantasticae asservandam dignitatem. [...] Hoc appellat primum animae vehiculum, medium inter temporalia et aeterna, quo plurimum vivimus,
} 
Esta relación entre la facultad imaginativa y los demonios será retomada setecientos años más tarde por el bizantino Miguel Psellos en uno de los tratados demonológicos más influyentes del medioevo: Sobre la actividad de los demonios. ${ }^{7}$ El pequeño tratado de Psellos es el más célebre de sus obras ya que condensa en un pequeño opúsculo la demonología neoplatónica de sus predecesores. En esta obra, el neoplatónico de Bizancio no solo caracteriza y clasifica las distintas clases de demonios, sino que también menciona las actividades y el comportamiento de estos seres. Así, en los siglos posteriores el opúsculo será conocido como "un breve y conciso manual de la materia" (Jiménez Flores, 2008: 5).

Psellos define a la imaginación -asentada en el pneûma-como susceptible de padecer la actividad demónica: los demonios introducen deseos y pensamientos a través de la imaginación para provocar pasiones en los hombres (ibid: 9). Esta relación entre imaginación y demonios será retomada por Giordano Bruno y será fundamental en la demonología presentada en el De magia naturali.

\subsection{Vinculum vinculorum amor est}

La tradición platónica en general y la demonología neoplatónica en particular son conocidas por Giordano Bruno gracias a la decisiva influencia que tienen las traducciones y los comentarios de Marsilio Ficino en su juventud. En esta sección queremos señalar la importancia de los conceptos de Eros y sympátheia -conceptos que Bruno conoce gracias a la obra del florentino- para comprender el lugar de los demonios en la obra del Nolano.

Sostenemos que, en el contexto de un pensamiento que concibe al mundo como un ser vivo y animado, Bruno, en su obra latina, requiere mediaciones en el espacio que hay entre la naturaleza finita del hombre y la infinita divinidad explicada en la naturaleza. ${ }^{8}$ Precisamente, la existencia de los demonios en los sistemas neoplatónicos viene a cumplir con este propósito y ocupará un lugar importante en el tratado latino De magia naturali (1590). En ese flujo continuo y perpetuo que es la naturaleza, tránsito gradual entre todas sus partes, habitan los seres espirituales conocidos como demonios. Ahora bien, estos demonios no deben ser comprendidos como seres sobrenaturales o extranaturales, sino como seres afines a los elementos de la naturaleza (agua, tierra, aire, fuego), esto es, insertos en la propia naturaleza de las cosas. Así pues, la capacidad de operar del hombre sobre los demonios-que, por otra parte, espiritualizan el espacio que ocupan- permite no sólo destacar la dignidad humana, sino también reivindicar a la naturaleza y a la materia. En este sentido, los seres espirituales que ocupan el espacio intermedio entre los hombres y los dioses resuelven un problema crucial en la cosmovisión neoplatónica: los demonios son el nexo, la unión entre hombres y dioses; y sin su mediación, la comunicación entre hombres y dioses se torna imposible. En efecto, el género de los demonios asegura la continuidad ontológica entre los planos terrestre y celeste. Esta idea puede remontarse al Banquete de Platón cuando Diotima instruye a Sócrates sobre los temas de Eros:

spiritus scilicet phantasticus; unum individuum omnia, quae sensus sunt, facit et recipit" (De Imaginum: 540-542) [De estas cosas resulta manifiesto que esta potencia es la efectora de las imágenes o por ella el alma es la efectora de las imágenes. A propósito de esto pongamos en medio el parecer de Sinesio el Platónico que así se explicó sobre el poder de la imaginación y el espíritu imaginativo: en la vigilia el sabio es hombre, pero Dios le hace partícipe de sí mismo mientras sueña, lo que nosotros adoptamos en defensa de la dignidad de la vida imaginativa. [...] el espíritu imaginativo, reclama [ser] el vehículo primero del alma, término medio entre lo temporal y lo eterno, por el que, sobre todo, vivimos; un individuo único hace y recibe todas las cosas que son propias del sentido] (De Imaginum: 352-353). Para un análisis del texto citado ver Gómez de Liaño, 1982a: 244-247.

7 Sobre Psellos y el De daemonibus ver Flores Jiménez, 2008.

8 La noción de una divinidad implícita que se "expresa" en la multiplicidad es desarrollada en extensión por Nicolás de Cusa. Para los conceptos de complicatio-explicatio véase Magnavacca, 2005: 144. 
Pues todo lo demónico es intermedio entre lo divino y lo mortal. [...] Como está en medio de ambos, rellena el intervalo, de modo que la totalidad esté estrechamente unida consigo misma. Gracias a él, es posible el arte adivinatoria en su integridad así como el arte sacerdotal que se ocupa de los sacrificios, las iniciaciones y los conjuros y toda profecía y la magia. El dios no se mezcla con el ser humano. Ahora bien, gracias a este daímon, hay todo tipo de trato y diálogo de los dioses con los hombres, tanto mientras éstos están despiertos como mientras duermen (Banquete 202e-203a: 147-149). ${ }^{9}$

Tres ideas conviene subrayar de este pasaje: en primer lugar, se plantea el espacio que ocupan los demonios como aquel que acorta la distancia entre lo divino y lo humano; en segundo lugar, se supone la existencia de lo demónico como principio sin el cual prácticas como la adivinación (manteía) y la magia (goeteía) no pueden llevarse a cabo; por último, la mediación demónica permite conservar la integridad de los dioses por fuera de la inclinación y el devenir. Sobre estas ideas se configurará la ciencia demonológica del neoplatonismo tardo-antiguo hasta llegar al siglo XVI, incluyendo, por supuesto, la doctrina de los demonios de Bruno.

En el Commentarium in Convivium Platonis, De amore (1469) Ficino retoma del discurso de Diotima la idea de Eros como un gran demonio (daimon mégas)..$^{10}$ En efecto, Eros es un ser intermedio: se encuentra entre la posesión de la belleza y la privación de esta. En palabras de Diotima, Eros es hijo de Penía (Pobreza) y Póros (Riqueza) (Banquete 203b-c). De ahí que el amante posee en parte lo que desea y en parte no.

Atque ita amorem ex huiusmodi mixtione medium quendam affectum esse volumus inter pulchrum et non pulchrum, utriusque participem. Ob hanc utique rationem Diotima ut ad eam iam veniamus, amorem daemonem appellavit, quia sicut daemones inter caelestia et terrena sunt medii, sic amor inter informitatem et formam medium obtinet (De amore VI.2).

Y de este modo consideramos que el amor, por esta mezcla, es un afecto intermedio entre lo bello y lo no bello, partícipe de uno y de otro. Y ciertamente, por esta razón Diótima, para volver ya a ella, llamo al amor demonio. Porque así como los demonios están en medio de las cosas celestes y las terrenas, así el amor ocupa el punto medio entre la ausencia de forma y la forma (De amore VI.2: 124).

La noción de Amor como demonio, esto es, mediador entre las cosas, la encontraremos desarrollada en Bruno como vinculum vinculorum (De vinculis: 522), a saber, el nexo más poderoso del que dispone el hombre-magus. Sumado a esto, otra idea neoplatónica fundamental para comprender la noción bruniana de amor como "vínculo de los vínculos" es la idea de simpatía (sympátheia). ${ }^{11}$

Uno de los autores clave para comprender esta idea es Plotino (205-270), conocido por los pensadores renacentistas -entre ellos Bruno- gracias a las traducciones y comentarios de Ficino. ${ }^{12}$ El filósofo alejandrino desarrolla en sus obras una de las ideas que más influenciaron en el pensamiento de los filósofos renacentistas: el mundo es una

9 Como se podrá observar, el pasaje de Platón sólo se limita a otorgar el papel de mediador y vínculo a Eros, el daímon mégas. La designación de esta función mediadora a otras entidades, los daímones, será llevada a cabo por la tradición neoplatónica y su lectura del discurso de Diotima.

10 Platón, Banquete 202e. Sobre los distintos usos del término daímon en Platón véase Rodríguez Moreno, 1994: 185-198.

11 Cabe mencionar-aunque no se desarrollará aquí- la presencia de influencias estoicas en el concepto de simpatía universal. Para la influencia de la pneumatología estoica en Ficino y Bruno ver Culianu, 1999: caps. I y V.

12 Plotino es considerado "el príncipe de los platónicos" por Bruno e, incluso, parece estimarlo como un filósofo superior a Platón (cf. De la causa: 204 y De umbris idearum: 63). 
realidad animada y viviente. El concepto clave de esta noción es el de sympátheia. Plotino plantea que en todas las cosas se encuentran ocultas relaciones de amistad y discordia que permiten vincular las distintas partes del universo. Por otra parte, la eficacia de las artes mágicas y la adivinación no se debe a la intervención del dios sobre el mundo sino, justamente, a la simpatía entre semejantes -y su contracara, la oposición entre desemejantes- que encontramos en las diversas partes de la naturaleza (cf. Enéadas IV.4 [28], 26 y 40). Esto lo lleva a decir que el universo es mago (goés) y hechicero (pharmakeús).

la verdadera magia consiste en la «Amistad» $\mathrm{y}$ «Discordia» que alternan en el universo, y el primer mago y hechicero es el universo, y como hay hombres que lo conocen a fondo, se valen de sus drogas y de sus hechizos para actuar unos sobre otros (Enéadas IV.4 [28], 40).

Esta idea la encontraremos citada en obras ficinianas como, por ejemplo, el De amore y el De vita, ${ }^{13}$ y tendría sus ecos en el naturalismo bruniano. En efecto, nosotros sostenemos que en este pasaje se halla la premisa básica sin la cual el mago y el sabio no pueden operar.

En el naturalismo bruniano, tanto en los diálogos italianos como en la obra latina, también encontramos la presencia de amistad y discordia en la naturaleza, esto es, la simpatía, que el verdadero mago y la verdadera magia deben conocer para actuar sobre ellas y contemplar la auténtica naturaleza de las cosas. A continuación, citaremos dos pasajes, uno del De la causa y otro del De magia naturali, que sostienen esta continuidad entre los diálogos italianos y la obra latina:

Certo (se ben misuramo) veggiamo che la corrozione non è altro che una generazione, e la generazione non è altro che una corrozione; l'amore è un odio, l'odio è un amore, al fine. L'odio del contrario è amore del conveniente; l'amore di questo è l'odio di quello. In sustanza dunque e radice, è una medesima cosa amore e odio, amicizia e lite. Da onde più comodamente cerca l'antidoto il medico, che dal veleno? [...] In conclusione, chi vuol sapere massimi secreti di natura, riguardi e contemple circa gli minimi e massimi de gli contrarii e oppositi. Profonda magia è saper trar il contrario dopo aver trovato il punto de l'unione (De la causa: 339-340).

Si medimos bien las cosas, veremos con claridad que la corrupción no es otra cosa que una generación y que la generación no es otra cosa que una corrupción; el amor es odio y el odio resulta ser un amor. El odio del contrario es amor del semejante, el amor de éste es odio de aquél. Amor y odio, amistad y discordia son por tanto una misma cosa en sustancia y raíz. ¿Dónde busca el médico el antídoto con más garantías que en el veneno? [...] En conclusión: quien quiera saber los más profundos secretos de la naturaleza, que mire y reflexione sobre los mínimos y los máximos de los opuestos y contrarios. Magia profunda es saber extraer el contrario después de haber hallado el punto de unión ( $D e$ la causa: $257-258$ ).

13 En las obras mencionadas, encontramos lo siguiente: "Qui amicitia daemonum magi evasisse videntur quemadmodum daemones magi sunt rerum ipsarum amicitiam cognoscentes, et natura omnis ex amore mutuo maga cognominatur" (De amore VI.10) [Así, parece que llegaron a ser magos por la amistad, que tuvieron con estos demonios, así como los demonios son magos porque conocen la amistad de las cosas mismas. Y toda la naturaleza es llamada maga por el amor recíproco] (De amore VI.10: 155). "Ubique igitur natura maga est, ut inquit Plotinus atque Synesius, videlicet certa quaedam pabulis ubique certis inescans, non aliter quam centro terrae gravia trahens, Lunae concavo levia, calore folia, humore radices, ceteraque similiter" (De vita III.26) [La naturaleza es por doquier hechicera, como dicen Plotino y Sinesio, y seduce a unas determinadas cosas con halagos bien determinados, derramados por todas partes, del mismo modo que atrae a los cuerpos pesados con el centro de la Tierra, a los ligeros con la cavidad de la Luna, a las restantes cosas] (De vita III.26: 165). 
sic corpus agit in corpus distans et in propinquum et in propriis partibus per consensum quendam, copulam et unionem, quae est a forma; et quia propterea omne corpus ab anima regitur seu spiritu quodam partes partibus connectente, ut accidit unam animam agere in alteram, ubique et undique sibi propinquam, ita etiam necessario evenit, ut agat in corpus, ubicunque sit illud quod illi animae subministrat atque subest. Qui noverit ergo hanc animae continuationem indissolubilem et eam corpori quadam necessitate adstrictam, habebit non mediocre principium, tum ad operandum, tum ad contemplandum verius circa rerum naturam (De magia naturali: 198).

Así es que un cuerpo actúa sobre un cuerpo distante o cercano y sobre sus propias partes por un cierto consentimiento, cópula o unión, que procede de la forma. Y puesto que todo cuerpo está regido por el alma o cierto espíritu que traba a las partes con las partes, así como acontece que un alma actúa sobre otra dondequiera ambas estén, así también resulta necesario que actúe sobre el cuerpo, encuéntrese dondequiera que sea el cuerpo que está supeditado al alma. Quien, por consiguiente, tenga conocimiento de esta indisoluble continuidad del alma y de que ésta se encuentra atada al cuerpo por una cierta necesidad, poseerá un principio no mediano tanto para obrar como para contemplar con más verdad la naturaleza de las cosas (De magia naturali: 243).

La magia es conocimiento de las simpatías que existen en las cosas. El conocedor de los efluvios que comprenden todas las partes del cosmos es capaz de canalizarlos y operar sobre la naturaleza. Esta es, pues, la definición de magia que el Renacimiento hereda de los antiguos. En palabras de Yates, el mago renacentista dispone del conocimiento de un complicado sistema de relaciones en el cual Todo es Uno; $y$, mediante ese conocimiento, es "capaz de penetrar en el interior de este sistema y servirse de él gracias a su conocimiento de los vínculos existentes entre las cadenas de influencias que descendían desde lo alto" (1983: 64). Los demonios -tanto si se entiende por este vocablo al Amor, a la influencia de los planetas o a entidades intermedias entre dioses y hombres- serán los seres que garantizarán la continuidad de esta cadena entre lo terrenal y lo celestial.

Hasta aquí hemos recuperado la influencia neoplatónica presente en las doctrinas demonológicas del Renacimiento. En este sentido, nos ha interesado señalar como fuentes de la demonología bruniana la teoría de la imaginación en Sinesio y Psellos, el concepto de Eros presente ya en el De amore de Ficino y la idea de sympátheia plotiniana. En el siguiente apartado mencionaremos las principales características de los demonios tal como aparecen en el De magia naturali y la afinidad de la imaginación y los vínculos con la actividad demónica en el filósofo Giordano Bruno. Ambos conceptos, imaginación y vínculos, obtienen su carácter filosófico de las doctrinas neoplatónicas que mencionamos en este apartado.

\section{Los demonios en el De magia naturali y De vinculis in genere de Gior- dano Bruno}

\subsection{La naturaleza de los demonios en el De magia naturali}

Como hemos desarrollado en el apartado anterior, los demonios ocupan un espacio intermedio entre los hombres y los dioses. Por esta razón, los demonios comparten características de ambas naturalezas: son inmortales como los dioses y, a su vez, participan de las sensaciones como los hombres. Teniendo en cuenta esto, Ficino escribe:

Animam mundi, id est materiae primae, et duodecim spherarum, et siderum animas deos Platonici nominant, tamquam angelicae mentis summique dei pedissequas. Animalia quae ignis aetheri sub luna locati, aut puri aeris, aut nebulosi aeris aquae proximi regionem habitant daemones. Quae terram incolunt rationalia, homines. Dii etiam immortales, et impatibiles sunt; homines patibiles, atque mortales sunt. Daemones immortales sunt 
quidem, sed patibiles (De amore VI.3).

Los platónicos llaman dioses al alma del mundo, esto es, de la materia primera, y las almas de las doce esferas y de las estrellas, puesto que siguen al sumo Dios y a la mente angélica; llaman demonios a los animales que, situados bajo la luna, habitan la región del fuego etéreo, del aire puro o del aire nebuloso, que está cerca del agua; y hombres a aquellos seres racionales que habitan la tierra. Los dioses son inmortales e impasibles, los hombres, mortales y pasibles, los demonios inmortales pero pasibles (De amore VI.3: 126-127).

La atribución de pasiones a los demonios es teóricamente importante ya que esta cualidad los distingue de la categoría de dioses. Por otro lado, el hecho de que los demonios sean susceptibles de padecer afecciones -placer y dolor- conlleva necesariamente a considerarlos como seres corpóreos. Los demonios habitan la región del aire; por lo tanto, su composición será predominantemente aérea. Si bien esto implica que poseen cuerpo, ese cuerpo será sutilísimo y, por esta razón, invisible ante nuestra mirada.

Como señala Delfina Giovannozzi, la capacidad de sentir dolor de los demonios tiene como consecuencia la posibilidad en el plano teórico de evocarlos mediante métodos naturales (2000: 88). Esta posibilidad es aprovechada por el mago renacentista. En el caso de Bruno, el magus que conoce las cualidades y los poderes de los demonios tiene la facultad de invocarlos e interrogarlos para obtener conocimientos y beneficios (Culianu, 1999: 199). Por supuesto, esta facultad es posible gracias a que los demonios sean corpóreos y capaces de sentir dolor. ${ }^{14}$

En el tratado De magia naturali, Bruno dedica todo un capítulo al estudio de los demonios que intitula De vinculis spirituum (Sobre los vínculos de los espiritus). Allí, el Nolano menciona seis clases de demonios, según el elemento que predomina en su complexión: 1) aéreos, 2) ígneos, 3) acuáticos, 4) terrestres, 5) subterráneos y 6) lucífugos (ibid: 249250). ${ }^{15}$ Entre estos demonios, los ígneos son enteramente buenos; los aéreos son buenos para algunos y hostiles para otros; y los acuáticos y terrestres, menos racionales, son enemigos o no son amigos. ${ }^{16}$ Resulta interesante señalar que Bruno apela a su propia experiencia para respaldar su conocimiento acerca de los demonios. Asegura, por ejemplo, haber visto demonios terrestres y acuáticos en los montes de Libero y Lauro. En otra ocasión, cuenta haber sido atacado por demonios -se sobreentiende lucífugos- bajo cierto risco al pie del monte Cicada en Nola (ibid: 253).

Bruno continúa su estudio diciendo que en los espíritus existen órdenes y jerarquías donde "hay presidentes y príncipes, pastores, jefes, rectores, graduaciones, entre los que los más sabios y poderosos mandan y están al frente de los más débiles y rudos" (De magia naturali: 251). El mago, pues, debe tener conocimiento de este orden para

14 "Daemones proinde esse corporeos et iuxta varia atque diversa genera corporum varios atque diversos; illud argumento est, quod affectus habent, libidines, iras, zelum, similia affectibus humanis et compositorum animalium crassioris sensibilisque materiae" (De magia naturali: 238) [Además, el que los demonios sean corpóreos y variados y diversos según los varios y diversos géneros de cuerpos es prueba de que tienen afectos, sensualidad, cóleras, celo y [afectos] semejantes a los humanos y [a los] de animales compuestos con materia grosera y sensible] (De magia naturali: 265).

15 Esta clasificación Bruno la toma de Psellos, a quien conoce mediante la traducción de Ficino. Los espíritus lucífugos son aquellos que rehúyen de la luz y, según la descripción de Bruno, son “lanzadores de piedras" (De magia naturali: 254).

16 Una postura más pesimista respecto de los demonios la encontramos en Psellos de quien, en este caso, Bruno se distanciaría: "Todas estas clases de demonios odian a Dios y son enemigos de los hombres, pero, como dicen, siempre hay algo peor que lo malo. En efecto, la especie acuática, la subterránea y la lucífuga son extremadamente maléficas y funestas: no dañan a las almas, me explicó, con fantasías o pensamientos, sino que se les lanzan encima como las más feroces de las fieras en busca de su destrucción. El acuático ahoga a los que van por las aguas, el subterráneo y el lucífugo, si se les consiente, se introducen en las entrañas y asfixian y vuelven epilépticos y dementes a los que han invadido. En cuanto a los aéreos y los terrestres, buscan y engañan taimadamente las mentes de los hombres, y los llevan a inusitados y crueles sufrimientos" (Psello, De Daemonibus: 30). 
poseer un control sobre la naturaleza demónica. ${ }^{17} \mathrm{El}$ desconocimiento de este sistema jerárquico entre los demonios no solo equivale a la imposibilidad de obtener favores de aquellos benéficos, sino también a encontrarse vulnerable al influjo de los demonios dañinos.

Ahora bien, ¿cómo sucede que los demonios inflijan daño a los seres humanos? Los demonios son espíritus o cuerpos sutilísimos y, como tales, pueden actuar directamente en el alma de los hombres. Como hemos mencionado anteriormente cuando recuperamos la teoría de la imaginación de Sinesio y Psellos, la puerta de entrada de los demonios al alma es el espíritu imaginativo: ellos deslizan deseos, pensamientos y recuerdos en el alma, turbando así sus sentidos.

Illis autem promptior est penetratio circa corpora et immissio cogitationum, quandoquidem usque adeo sensibus internis impressiones quasdam obtrudunt, ut ea quae ipsi suggerunt, per nosmetipsos excogitare videamur interdum [...] daemoni vero ne auribus ipsis quidem opus est, neque voce, neque susurru, sed sensum ipsum internum ita penetrat, ut dictum est. Sic immittunt somnia non solum et faciunt voces exaudiri et quaecunque videri, sed etiam vigilantibus certas cogitationes, quas ab alio vix esse cognoscantur, interdum per aenigmata, interdum expressioribus sensibus veritatem inculcantes, interdum fortasse decipientes (De magia naturali: 222-224).

Para los demonios es más fácil penetrar por los cuerpos e introducir pensamientos; hasta tal punto taponan nuestros sentidos con ciertas impresiones sensibles, que a veces nos llega a parecer que estamos imaginando por nosotros mismos aquellas cosas que ellos nos sugieren [...]. El demonio empero no necesita siquiera de oídos, ni de voz, ni de susurro, sino que penetra en el sentido interno de la manera en que se ha dicho. Así no sólo introducen sueños y hacen oír voces y ver algunas cosas, sino que incluso a veces durante la vigilia introducen ciertos pensamientos -que a duras penas se los reconocerá como procedentes de otro- a veces por medio de enigmas, a veces conculcando la verdad con sentidos más expresos, a veces poco más o menos que engañando (De magia naturali: 247-248). ${ }^{18}$

Así como los demonios pueden habitar los cuerpos humanos y agitar el alma individual, existen demonios que habitan animales, plantas y minerales. Todo el cosmos se encuentra pleno de espíritus que fluctúan de sitio en sitio continuamente. ${ }^{19}$ Dos principios filosóficos fundamentales que el Nolano presenta en los diálogos londinenses encuentran su correlato en esta idea. En primer lugar, la noción de que todo el universo se encuentra animado por el alma del mundo. Así, no hay materia que no esté preñada de formas. ${ }^{20}$ Los demonios no se encuentran fuera de este universo

17 Sobre si es posible "desdemonizar" la magia bruniana, remitimos al trabajo de Paolo Rossi, especialmente el capítulo 4 titulado Bruno, i moderni, la magia (2006: 131-183), y al reciente estudio de Manuel Mertens, en particular el capítulo A SpiritRegulating Art (2018: 150-217).

18 Bruno utiliza el concepto de sensus internus. En la obra De imaginum, signorum et idearum compositione, Bruno llama a la phantasía sentido de los sentidos, "puesto que el propio espíritu imaginativo es el sensorio más común y el cuerpo primero del alma". En este sentido, "el sentido íntimo está por entero en todas partes; pues oye con todo el espíritu [y] con todo el espíritu ve" (De Imaginum:352) [Haec [phantasia] enim sensus est sensuum, quoniam phantasticus ipse spiritus sensorium est communissimum primumque animae corpus [...]. Intimus interea sensus in cunctis suis partibus est integer: toto namque spiritu audit, toto videt] (De Imaginum: 540). Que este concepto alude a la imaginación en el párrafo del De magia naturali citado se esclarece aún más remitiéndonos a la fuente directa que utiliza Bruno. En efecto, leemos en el De daemonibus de Psellos que los demonios "se acercan a nuestro espíritu imaginativo (phantasticum seu imaginativam spiritum) y, espíritus como son también ellos, nos susurran palabras sobre sensaciones y placeres, no con voces estridentes ni ruidosas, sino instiladas por ellos sin ruido alguno" (De daemonibus: 30$)$. Sobre las fuentes del concepto de sentido interno y su relación con la imaginación, véase Priani Saisó, 2002: 117 y ss.

19 Cf. Mertens, 2018: 196: "It goes without saying that such a spiritualized infinite universe offers an ideal habitat for demonic spirits".

20 La filosofía de Giordano Bruno es una reivindicación de la materia respecto a la tradición platónica y aristotélica. La concepción bruniana de la materia entendida como divina -contrapuesta a la concepción de materia como prope nihil- la encontramos, entre otras obras, en De la causa IV, y en De vinculis XV: "Dunque si de' piú tosto dire che contiene le forme e che le includa, che pensare, che ne sia vota e le escluda. Quella, dunque, che esplica lo che tiene implicato, debe essere chiamata cosa divina e ottima parente, genetrice e madre di cose natural, anzi la natura tutta in sustanza" (De la causa:311-312) 
animado: no hay lugar para realidades sobrenaturales en el naturalismo bruniano ni en su concepción de la naturaleza como imagen o espejo de la divinidad. En Bruno, el conocimiento de la naturaleza de los seres intermediarios conocidos como demonios es, al mismo tiempo, un indagar en los misterios de la naturaleza. En segundo lugar, la noción de vicissitudine ${ }^{21}$ es decir, la alternancia constante de todas las cosas en el universo. La divinidad se manifiesta en la naturaleza a través de la continua mutación de los contrarios en sus opuestos. Esto lo lleva a decir a Bruno que no hay muerte, sino separación y composición incesante. ${ }^{22}$

\begin{abstract}
et nusquam spiritus aeternam sedem sibi destinatam comparavit, sed fluctuat materia de uno in alium spiritum et naturam seu compositionem, fluctuat spiritus de una in aliam materiam; et hoc est alteratio, mutatio, passio et tandem corruptio, nempe partium certarum et a certis partibus segregatio et cum certis compositio; nam mors aliud non est praeterquam dissolutio. Atqui neque spiritus ullus nec corpus ullum interit, sed complexionum tantum et actuum mutatio est continua (De magia naturali: 230 ).
\end{abstract}

en ningún lugar espíritu [alguno] se procuró y asignó un asiento eterno, sino que la materia fluctúa de uno a otro espíritu, naturaleza o composición, [o bien] el espíritu fluctúa de una en otra materia; y esto es la alteración, la mutación, la pasión y, por último, la corrupción, a saber, la separación de ciertas partes respecto de ciertas partes y la composición de ciertas partes con ciertas partes; pues la muerte no es más que la disolución. Sin embargo, ni el espíritu ni el cuerpo mueren, sino que hay sólo una continua mutación de complexiones y actos (De magia naturali: 251-252).

Como podemos observar, la demonología presentada en el De magia naturali se encuentra íntimamente ligada con la cosmología y metafísica expuestas en los diálogos londinenses. Por otro lado, y de acuerdo con Giovannozzi (2000: 81) en este análisis, la demonología bruniana aparece perfectamente integrada en la tradición neoplatónica. En el siguiente apartado, abordaremos la obra De vinculis in genere como la segunda gran parte de la magia del Nolano: la primera consiste en su demonología; la segunda en el arte de generar vínculos.

\title{
3.2. Vínculos e imaginación en Giordano Bruno
}

La doctrina de la magia bruniana quedaría incompleta si sólo se refiriese a la demonología. La aplicación y perfección de la magia sólo encuentra su culminación en el arte de los vínculos, esto es, en la operación de administrar los influjos del spiritus y unir las cosas -entre sí y con la totalidad de la naturaleza- por medio de sus correspondencias intrínsecas.

El arte de los vínculos se encuentra desarrollado en la obra De los vínculos en general (De vinculis in genere), un pequeño tratado incompleto que hace de manual práctico para la aplicación de los conocimientos acumulados por el mago (Culianu, 1999: 141). El hecho de que este tratado se haya encontrado junto al De magia naturali en

[por lo que debemos decir que ella [la materia] contiene las formas y las incluye en sí antes que pensar que esté vacía de ellas y las excluya. En consecuencia: ella, que explica lo que tiene implicado, es quien debe ser llamada cosa divina, óptima progenitora, engendradora y madre de las cosas naturales, incluso la naturaleza toda en sustancia] (De la causa: 212-213). "Eiusmodi est materia per universum, extra quam nulla est forma, in cuius potentia, appetitu et dispositione omnes sunt formae, et quae in partibus suis vicissitudine quadam omnes recipit formas, quarum simul vel duas recipere non posset. Et divinum ergo quoddam est materia, sicut et divinum quoddam existimatur esse forma, quae aut nihil est, aut materiae quiddam est" (De vinculis: 518 ) [Tal es la materia a través del universo, fuera de la cual no existe ninguna forma; en la potencia, el apetito y el orden de la cual radican todas las formas; y la que mediante cierta vicisitud recibe en sus partes todas las formas, de las cuales no puede admitir dos o más al mismo tiempo. Por consiguiente, la materia es además alguna cosa divina, del mismo modo como también se considera que sea alguna cosa divina la forma, la cual o no es nada o bien es algo de la materia] (De vinculis: 96).

21 Para el concepto de vicissitudine en la obra del Nolano véase Granada, 2005: 215-259.

22 Cf. De la causa: $112-113$ y $144-145$ 
el códice Noroff no hace más que confirmar esta apreciación: el De vinculis es la parte práctica de la magia bruniana y complementa la teoría del De magia naturali.

La importancia del concepto de vínculo (vinculum) y el rango teórico que adquiere este vocablo en la obra del Nolano es señalado por autores como Ioan Culianu (ibid: 129-153) y Ernesto Schettino (2008: 30-31), entre otros. Vinculum puede definirse como el medio por el cual se reúnen las partes del universo a partir de sus correspondencias ocultas y, para completar esta acción, se necesitan tres cosas: la potencia activa en el agente (potentia activa in agente), la disposición o la potencia pasiva en el sustrato (potentia passiva in subiecto seu patiente seu dispositio) y la correcta aplicación (debita applicatio) atendiendo a circunstancias tales como tiempo y lugar (cf. De magia naturali: 256). En suma, aquel que vincula debe poseer un conocimiento del conjunto de las cosas para poder operar sobre ellas, llevando a término el perfil del magus delineado al principio del De magia naturali: mago es el hombre sabio con poder de obrar. ${ }^{23}$

[Ut] eum qui vincire debet necessarium est rerum quodammodo universalem rationem habere, ut hominem -qui epilogus quidam omnium est- valeat, alligare, quandoquidem -ut alibi diximus-in hac potissimum specie rerum omnium species maxime per numeros licet intueri (De vinculis: 414$)$.

Aquel que está obligado a establecer vínculos necesita de algún modo poseer una concepción general de la realidad para que sea capaz de ligar al hombre (que es un cierto compendio de los demás seres), puesto que, como hemos dicho en otro lugar, es particularmente en esta especie donde es posible contemplar las especies de todas las cosas, sobre todo a través de categorías (De vinculis: 41).

$* * *$

Vincire ergo novit, qui universi rationem habet, vel saltem rei particularis vinciendae naturam, dispositionem, inclinationem, habitum, usum, finem (De vinculis: 428 ).

Por consiguiente, sabe vincular quien tiene una explicación del conjunto de las cosas o, por lo menos, de la naturaleza, la disposición, la inclinación, el hábito, el uso, el fin de la cosa particular a vincular (De vinculis: 49).

Esta doctrina de los vínculos sólo tiene sentido en un universo en el cual todas sus partes se encuentran relacionadas entre sí, donde Todo es Uno. Hemos mencionado anteriormente que una de las funciones de los demonios es llenar el espacio entre el mundo terrenal y el mundo divino, y que el demonio que más poder vincular tiene es Eros (vinculum vinculorum amorest). Giordano Bruno es el autor que lleva la identidad entre Eros y magia -hablamos por ello de una "magia erótica" en Bruno- hasta sus últimas consecuencias (Culianu, 1999: 130).

Divina vis quaedam est in rebus omnibus; amor ipse pater, fons et Amphitrites est vinculorum. Ideo non perperam Orpheus et Mercurius ipsum «magnum daemona» appellant, quippe et tota rerum substantia, constitutio et -ut ita dicam- hypostasis vinculum quoddam est. Maximam ergo et principem vinculi doctrinam assequemur, ubi ad ordinem universi oculos convertemus. Hoc vinculo superiora provident inferioribus, inferiora convertuntur ad superiora, paria invicem associantur, universi tandem perfectio est secundum formae rationem (De vinculis: 510 ).

23 "Cuando los filósofos lo usan entre ellos mismos, entonces mago significa hombre sabio con poder de obrar" (De magia naturali: 229) [tunc magus significat hominem sapientem cum virtute agendi] (De magia naturali: 166). 
En todas las cosas reside una determinada fuerza divina y ésta es el amor mismo, el padre, la fuente y Anfitrite de los vínculos. De aquí que por ello no erróneamente Orfeo y Mercurio llaman al mismo gran Demonio, como que también la entera sustancia, la estructura y -por decir así- la hipóstasis de la realidad consiste en un cierto vínculo. Por consiguiente, alcanzaremos la máxima y principal teoría de los vínculos cuando volvamos los ojos hacia el orden del universo. Por medio de este vínculo las cosas superiores proveen a las inferiores, las cosas inferiores se dirigen hacia las superiores, las cosas pares se relacionan mutuamente, en una palabra, tiene lugar la perfección del universo conforme a la disposición de la forma (De vinculis: 91-92).

Así pues, el "gran demonio", Eros, impregna la totalidad de las cosas y hace de la naturaleza un gran vínculo (resuena aquí la fórmula neoplatónica "la naturaleza es una gran maga" que encontramos en Plotino y Ficino). Los vínculos copulativos que el mago elabora derivan directamente de Eros, llevando a cabo una erotización de la magia, ${ }^{24}$ doctrina que tiene sus raíces en el discurso que Diotima da a Sócrates. Ahora bien, gracias a la continuidad ontológica otorgada por Eros, la naturaleza toda se revela plena de espíritu, llena de vida. Este espíritu, pneûma o anima mundi, es la sustancia común y única que contiene a todos los seres y sus relaciones mutuas, y sobre esta sustancia se realizan las operaciones mágicas y eróticas del mago (Culianu, 1999: 129-130).

El espíritu, cuerpo sutilísimo, tercer elemento que media entre el cuerpo y el alma (Cf. Ficino, De vita III.3), solo puede ser aprovechado por aquella facultad que comparte sus mismas características, esto es, la imaginación (imaginatio-phantasía). ${ }^{25}$

Omnibus hisce modis cum contingat vinciri et obligari sensum, medico seu mago maxime insistendum est circa opus phantasiae; hoc enim est porta et praecipuus aditus ad actiones et passiones affectusque universos, qui sunt in animali; ex hac etiam alligatione sequitur alligatio profundioris potentiae, quae est cogitativa (De magia naturali: 280 ).

Cuando acontezca vincular y obligar al sentido según todos estos modos, el médico o mago ha de insistir sobre todo en el poder operativo de la fantasía; pues ésta es la puerta y entrada principal para todas las acciones, pasiones y afectos que se encuentran en el animal; y la vinculación de ésta ocasiona la vinculación de aquella potencia más profunda que es la cogitativa (De magia naturali: 276).

Bruno resalta en su obra el poder operativo de la fantasía por sobre la razón a la hora de realizar vínculos: "quien desea vincular tenga la certeza de que la razón no desempeña ni el mayor ni el principal papel para conseguir ligar" (De vinculis: 77). Esto se debe a que la fantasía tiene una afinidad con el spiritus mundi que la razón no posee: el spiritus presente en el universo, por un lado, y la condición pneumática

24 "Bruno erotiza la tarea mágica, sexualiza el cosmos y la espiritualidad, de tal manera que el mago aparece como extraño sacerdote del «amor mágico», como conjunción copulativa del texto universal” (Gómez de Liaño, 1982b: 221). Por otro lado, encontramos en Ficino la idea del amor como magus, lo que nos permite entablar una continuidad entre la magia ficiniana y la magia bruniana: "Sed cur magum putamus amorem? Quia tota vis magicae in amore consistit. Magicae opus est attractio rei unius ab alia ex quadam cognatione naturae. Mundi autem huius partes, ceu animalis unius membra, omnes ab uno auctore pendentes, unius naturae communione invicem copulantur. Ideo sicut in nobis cerebrum, pulmones, cor, iecur, et reliqua membra a se invicem trahunt aliquid, seque mutuo iuvant, et uno illorum aliquo patiente compatiuntur, ita ingentis huius animalis membra, id est, omnia mundi corpora connexa similiter mutuant invicem naturas et mutuantur; ex communi cognatione communis innascitur amor, ex amore communis attractio. Haec autem vero magica est" (De amore VI.10) [Pero, ¿por qué imaginamos al amor mago? Porque toda la fuerza de la magia se basa en el amor. La obra de la magia es la atracción de una cosa por otra por una cierta afinidad natural. Las partes de este mundo, como miembros de un solo animal, dependiendo todos de un solo autor, se unen entre sí por su participación de una sola naturaleza. Y así como en nosotros el cerebro, el pulmón, el corazón, el hígado y los otros miembros sacan el uno del otro alguna cosa, se favorecen recíprocamente y padecen conjuntamente si uno de ellos sufre, así los miembros de este gran animal, o sea, todos los cuerpos del mundo unidos entre sí igualmente prestan y toman prestadas sus naturalezas. De la común afinidad nace el amor común. Nace la atracción común. Y esta es la verdadera magia] (De amore VI.10: 153-154).

25 Sobre este punto cf. Priani Saisó, 2002: 113-122. 
de la fantasía, por el otro lado, se corresponden por compartir la misma naturaleza. El magus, por lo tanto, deberá purificar su propio spiritus para unirse con el spiritus del mundo y obtener beneficios naturales (cf. Ficino, De vita III.4: 98). De más está decir que mediante esta operación se pueden obtener beneficios tanto de las estrellas como de los demonios, pues los demonios se comunican con los hombres mediante el spiritus phantasticus. ${ }^{26}$

\section{A modo de conclusión}

En este trabajo nos hemos propuesto abordar la doctrina de los demonios de Giordano Bruno en el marco de su filosofía. Por ello, hemos indicado que, sin este marco filosófico que comienza a delinearse en los diálogos italianos, no es posible comprender la demonología presente en su obra latina. A su vez, hemos señalado algunas de las principales fuentes neoplatónicas de la demonología de los siglos XV y XVI que Bruno toma en cuenta para el desarrollo de la doctrina de los demonios del De magia naturali. Por último, nos hemos detenido en desarrollar la relación entre la demonología, los vínculos e imaginación en el pensamiento de Bruno.

La preocupación por la intermediación entre los planos celeste y terrestre, por un lado, y la relación entre vida contemplativa y vida activa, por el otro, son esenciales en la filosofía del Renacimiento. Como pudimos observar, Bruno no escapa a estas preocupaciones, y tanto la magia como la demonología se encuentran insertas en ellas. Sin embargo, otros problemas surgen de estas doctrinas.

La existencia de seres intermedios -tanto benéficos como dañinos- que ocupan el espacio entre el hombre y lo divino en la naturaleza conlleva una preocupación por el cuidado tanto del cuerpo y del alma (en el caso de Ficino) como de la facultad imaginativa (en el caso de Bruno). Asimismo, la distinción entre una magia natural y una acepción indigna de magia se encuentra presente en el marco teórico de ambos autores. Recordemos que el tratado De magia naturali de Bruno comienza con una caracterización de distintas concepciones de magia, dentro de las cuales sólo la última, propia de "ciertos rudos, cual fue aquel que escribió el libro De malleo maleficiarum", parece ser censurada por Bruno (De magia naturali: 229). ${ }^{27}$

La obra de Giordano Bruno presenta una singular conjunción de filosofía natural y magia. Los supuestos metafísicos expuestos en los diálogos italianos (el monismo ontológico, la infinitud del universo, la continuidad espiritual del Todo a partir del alma universal) sirven de marco teórico para las obras mágicas y mnemotécnicas de sus obras latinas -incluyendo el capítulo sobre demonología inserto en el De magia naturali (Gómez de Liaño, 1982b: 211)-. En otras palabras, la magia y la demonología de las obras latinas supone la cosmología presentada en los diálogos londinenses donde el universo se encuentra unido por un flujo continuo y perpetuo, de manera que se puede realizar el tránsito entre todas sus partes (cf. De vinculis: 91 y De magia naturali: 230-231).

\footnotetext{
26 Ya hemos mencionado las reservas presentes en el De vita de Ficino respecto a la obtención de beneficios por parte de los demonios. Sin embargo, creemos que pasajes como el siguiente abrirían la puerta a esa posibilidad: "Hunc tu igitur studebis tibi imprimis insinuare, hoc enim medio naturalia quaedam beneficia reportabis, tum corporis mundani, tum animae, tum etiam stellarum atque daemonum" (De vita III.4:) [Ahora, pues, tú procurarás ante todo que este espíritu penetre en ti, pues con este medio obtendrás algunos beneficios naturales, procedentes ya del cuerpo o ya del alma del mundo, y también de las estrellas y de los demonios ] (De vita III.4: 98). Para la magia astral de Ficino remitimos al artículo de Robles García y Toledo Marín, 2013: 189-209.

27 Hace referencia Bruno a los inquisidores Heinrich Kraemer y Jakob Sprenger, quienes publican en 1487 el Malleus maleficarum
} 
El filósofo natural, pero también el mago, tienen la tarea de descubrir las diversas mediaciones que confluyen en el universo para poder operar en el mundo y emplear las virtudes y poderes ocultos de la naturaleza. Debe conocer la relación entre macrocosmos y microcosmos para obtener beneficios de la "cadena de ser" que conecta lo celestial y lo terrestre, desde los astros hasta los minerales: la teoría tiene como fin la praxis. El magus, conocedor del orden natural, deviene de esta manera el hombre del Pimander hermético (Gómez de Liaño, 1982b: 214), o el segundo dios (secundus deus) del Asclepius (cf. D’Amico, 2016:38), que actúa en la naturaleza y se percibe parte (microcosmos) del organismo viviente que es el universo (macrocosmos). Aquel hombre capaz de armonizar su propio spiritus con el spiritus del mundo tiene la posibilidad de emplearlo y perfeccionarse tanto a sí mismo como al mundo. En esta empresa, la imaginatio/phantasía ocupa un papel destacado. ${ }^{28}$

En conclusión, observamos una continuidad entre la doctrina demonológica que Bruno presenta en su obra latina y la metafísica y cosmología de los diálogos italianos. Con Bruno asistimos a la recuperación de doctrinas neoplatónicas y herméticas (tales como la demonología, la magia natural, la simpatía universal, etc.) que derivan en una comprensión animista y dinámica de la naturaleza. A su vez, la importancia del hombre en tanto actuante dentro del universo tiene como principal fundamento la figura del mago renacentista, es decir, del sabio conocedor de los secretos de la naturaleza y capaz de actuar en ella. Así pues, el pensamiento de Giordano Bruno demuestra la potencia de la interpretación de Aby Warburg según la cual la magia es una especie de "cosmología aplicada" (cf. Klibansky, Panofsky y Saxl, 1991: 113). 


\section{Bibliografía}

\section{Fuentes}

\section{Ediciones}

» Giordano Bruno (1958). Dialoghi italiani. Ed. Gentile, G. 3ra ed. a cargo de Giovanni Aquilecchia. Florencia: Sansoni.

» Giordano Bruno (2000). Opere magiche. Eds. Ciliberto, M., Bassi, S., Scapparone, E. y Tirinnanzi, N. Milán: Adelphi.

" Giordano Bruno (2009). Opere mnemotecniche II. Eds. Ciliberto, M., Matteoli, M., Sturlese, R. y Tirinnanzi, N. Milán: Adelphi.

» Marsilio Ficino (1944). Commentary on Plato's Symposium. Ed. y trad. Sears Reynolds Jayne, A. M. Columbia: University of Missouri.

» Marsilio Ficino (1989). Three books on life. Ed. y trad. Kaske, C. V. y Clarke, J. R. Nueva York: Renaissance Society of America.

\section{Traducciones}

" Giordano Bruno (1982). "Sobre Magia" (De magia naturali). Trad. Gómez de Liaño, I. En: Idem. Mundo. Magia. Memoria. Madrid: Taurus, 225-280.

»Giordano Bruno (1982b). Sobre la composición de imágenes (De imaginum, signorum et idearum compositione). Trad. Gómez de Liaño, I. En: Idem. Mundo. Magia. Memoria. Madrid: Taurus, 313-384.

» Giordano Bruno (2008). De vinculis in genere. Trad. Schettino, E. México: Editorial Pax México.

" Giordano Bruno (2009). Las sombras de las ideas. Trad. Reventós, J. Madrid: Siruela.

» Giordano Bruno (2018). De la causa, el principio y el uno. Trad. Granada, M. Á. Madrid: Tecnos.

» Marsilio Ficino (1994). De amore. Comentario a «El Banquete» de Platón. Trad. de la Villa Ardura, R. Madrid: Tecnos.

" Marsilio Ficino (2006). Tres libros sobre la vida. Trad. Villanueva Salas, M. Madrid: Asociación Española de Neuropsiquiatría.

» Miguel Psello (1991). "Sobre la actividad de los demonios". En: Opúsculos. Trad. Curbera Castello, J. Madrid: Ediciones Clásicas.

»Platón (2015). Banquete. Trad. Ludueña, E. Buenos Aires: Colihue.

» Plotino (1985). Enéadas III-IV. Trad. Igal, J. Madrid: Gredos.

" Sinesio (1993). "Sobre los sueños". En: Himnos. Tratados. Trad. García Romero, F. A. Madrid: Gredos.

\section{Bibliografía complementaria}

»Cassirer, E. (1951). Individuo y cosmos en la filosofía del Renacimiento. Trad. Bixio, A. Buenos Aires: Emecé. 
" Clark, S. (1997). Thinking with Demons: The Idea of Witchcraft in Early Modern Europe. Oxford: Clarendon Press.

"Clucas, S. (2004). "Mnemosine in London: The Art of Memory and Giordano Bruno's Spaccio de la bestia trionfante and Degli eroici furori", Bulletin de la société d'études anglo-américaines des XVIle et XVIIle siècles 58, 7-23.

"Copenhaver, B. (1987). "Iamblichus, Synesios and The Caldean Oracles in Marsilio Ficino's De vita libri tres. Hermetic Magic or Neoplatonic Magic?". En: Hankins, J., Monfasani, J. y Purnell, F. (eds.). Supplementum Festivum. Studies in Honor of Paul Oskar Kristeller. Nueva York: Medieval and Renaissance Texts and Studies, 441455.

" Cornford, F. M. (1957). From Religion to Philosophy. A Study in the Origins of Western Speculation. Nueva York: Harper Torchbook.

»Culianu, I. (1999). Eros y magia en el Renacimiento. Trad. Clavera, N. y Rufat, H. Madrid: Siruela.

"De Garay, J. (2016). "Magia y neoplatonismo en Ficino". En: Rodríguez Valls, F. y Padial, J. J. (coords.). Hombre y cultura. Estudios en homenaje a Jacinto Choza. Sevilla: Thémata, 217-232.

» D'Amico, C. (coord.) (2016). Asclepio. Un texto sapiencial. Buenos Aires: Editorial de la Facultad de Filosofía y Letras de la Universidad de Buenos Aires.

» Flores Jiménez, A. (2008). "Sobre la actividad de los demonios: un tratado medieval bizantino sobre demonología”, Revista Digital Universitaria 9.12, 3-13.

"Garin, E. (1981). El zodiaco de la vida. La polémica astrológica del trescientos al quinientos. Trad. Moya, A. Barcelona: Península.

" Garin, E. (1993). “El filósofo y el mago". En: El hombre del Renacimiento. Madrid: Alianza, 165-195.

" Giovannozzi, D. (2000). "Porphyrius, Plotinus et alii platonici. Echi neoplatonici nella demonologia bruniana", Bruniana \& Campanelliana 6.1, 79-105.

» Gómez de Liaño, I. (1982a). El idioma de la imaginación. Madrid: Taurus.

"Gómez de Liaño, I. (1982b). "Bruno el mago: demonios y vínculos". En: Idem. Mundo. Magia. Memoria. Madrid: Taurus, 211-224.

" Granada, M. Á. (2015). "Introducción”. En: Giordano Bruno. La cena de las cenizas. Trad. Granada, M. Á. Madrid: Tecnos, XIII-CCXXXIV.

» Granada, M. Á. (2005). La reivindicación de la filosofía en Giordano Bruno. Barcelona: Herder.

»Greif, E. y Szapiro, A. (2012). "La percepción de Giordano Bruno en la historiografía reciente". En: Selvático, L., Bozzoli, M. y Pesenti, L. (eds.). Epistemología e Historia de la ciencia. Córdoba: Universidad Nacional de Córdoba, 251-256.

» Hirai, H. (2012). "Medicina e astrologia. Aspetti della medicina astrale platonica". En: Ernst, G. y Giglioni, G. (eds.). Il linguaggio dei cieli: astri e simboli nel Rinascimento. Roma: Carocci, 205-221.

»Klibansky, R., Panofsky, E. y Saxl, F. (1991). Saturno y la melancolía: Estudios de historia de la filosofía de la naturaleza, la religión y el arte. Trad. Balseiro, M. L. Madrid: Alianza.

» Luck, G. (1995). Arcana Mundi. Trad. Gallego Moya, E. y Pérez Molina, M. E. Madrid: Gredos. 
" Magnavacca, S. (2005). Léxico técnico de filosofía medieval. Buenos Aires: Miño y Dávila.

» Mertens, M. (2018). Magic and Memory in Giordano Bruno: the art of a heroic spirit. Boston: Brill.

» Priani Saisó, E. (2002). “Fantasía, imaginación y vínculos mágicos en Giordano Bruno". En: Benítez, L. y Robles, J. (coords.). Giordano Bruno (1600-2000). México: UNAM, 113-122.

» Robles García, J. A. y Toledo Marín, L. (2013). "Curarse con los astros: un estudio del De vita III de Marsilio Ficino". En: Benítez Gorbet, L. y Velázquez Zaragoza, A. (coords.). Tras las huellas de Platón y el platonismo en la filosofía moderna: De su simiente griega a la ilustración. México: Facultad de Estudios Superiores Acatlán, 189-209.

» Rodríguez Moreno, I. (1994). “Démones y otros seres intermedios entre el hombre y la divinidad en el pensamiento platónico", Fortunatae. Revista canaria de filología, cultura y humanidades clásicas 6, 185-198.

» Rossi, P. (2006). Il tempo dei maghi. Rinascimento e modernità. Milán: Raffaello Cortina Editore.

» Thorndike, L. (1923). A History of Magic and Experimental Science, Vol. I. Nueva York / Londres: Columbia University Press.

»Walker, D. P. (2000). Spiritual \& demonic magic: from Ficino to Campanella. Pensilvania: The Pennsylvania State University Press.

» Yates, F. A. (1983). Giordano Bruno y la Tradición Hermética. Trad. Bergadá, D. Barcelona: Ariel. 